\title{
Effects of 20-hydroxyecdysone on the development and morphology of the red flour beetle, Tribolium castaneum (Coleoptera: Tenebrionidae)
}

\author{
NuJiRa TATUN ${ }^{1}$, PhiRAYa KUMDI ${ }^{1,2}$, JATUPorn TUNGJITWITAYAKUL ${ }^{1}$ and Sho SAKURAI ${ }^{3}$ \\ ${ }^{1}$ School of Science, University of Phayao, Phayao 56000, Thailand; e-mails: nujira.ta@up.ac.th, t jatuporn@hotmail.com \\ 2 Department of Entomology and Plant Pathology, Faculty of Agriculture, Chiangmai University, Chiangmai 50200, Thailand \\ ${ }^{3}$ Division of Life Sciences, Graduate School of Natural Science and Technology, Kanazawa University, Kanazawa 920-1192, \\ Japan; e-mail: ssakurai@staff.kanazawa-u.ac.jp
}

Key words. Coleoptera, Tenebrionidae, Tribolium castaneum, 20-hydroxyecdysone, wing growth, $\alpha$-amylase, prothetelic

\begin{abstract}
The red flour beetle, Tribolium castaneum, is a pest of stored products. It is also regarded as a model species for studying development, genetics, biology, physiology and biochemistry. Recently, it has become a model for use in RNA interference experiments. 20-hydroxyecdysone (20E) is involved in insect metamorphosis and its role in organ development in T. castaneum are based on hormonal treatment in conjunction with RNAi. However, information on the biological, morphological and physiological effects of $20 \mathrm{E}$ on $T$. castaneum is still limited. This study reveals the responses of $T$. castaneum larvae to injections with various doses of $20 \mathrm{E}(100,200,300,400$ and $500 \mathrm{ng} / \mathrm{insect})$. The results show that larvae injected with $20 \mathrm{E}$ reached the prepupal, pupal and adult stages earlier than the control group. Different degrees of morphological change were observed in nine traits, including the appearance of pupal prothetelic organs in the larvae. Moreover, an injection of a high dose of $20 \mathrm{E}$ reduced the body weights of the resulting insects at each stage, as well as the length and width of elytra. The enzymatic activity of $\alpha$-amylase in the resulting adults also decreased significantly. This indicates that injection of $20 \mathrm{E}$ caused precocious metamorphosis in $T$. castaneum by inducing changes in morphology and a-amylase activity, and the optimal concentrations that induce such phenomena were in the range of 100-200 ng/insect. Further investigations are needed to examine the roles of $20 \mathrm{E}$ in the regulation of $\alpha$-amylase in T. castaneum.
\end{abstract}

\section{INTRODUCTION}

The red flour beetle Tribolium castaneum (Herbst) (Coleoptera: Tenebrionidae) is an important pest of stored products, especially in tropical areas. However, it has also been used as a model species for development and genetic studies (Kingler, 2004). Recently, its genome was completely sequenced, resulting in $T$. castaneum becoming an important model for RNA interference experiments for exploring the functions of genes. There are numerous reports of the high efficiency of RNAi in T. castaneum, and it is thus regarded as a valuable system for studying any basic problem in insect biology and physiology.

The steroid hormone 20-hydroxyecdysone (20E) is a major developmental hormone in insects and is involved in various developmental transitions, including ecdysis and metamorphosis. This hormone functions by activating target genes in a stage-specific and tissue-specific manner. In the last larval instar, high levels of ecdysone initiate the transition to pupal development (Smagghe, 2009). There are many reports of using RNAi in conjunction with treatments of $20 \mathrm{E}$ or juvenile hormone to reveal the relationship between a gene of interest and its hormonal regula- tion. One such study reports that $20 \mathrm{E}$ regulates ovarian growth, oocyte maturation and the development of T. castaneum (Parthasarathy et al., 2010). Mid gut remodeling in $T$. castaneum is also regulated by $20 \mathrm{E}$ according to an RNAi experiment with the Broad gene $(T c B r)$ (Parthasarathy et al., 2008).

There are many reports on the involvement of RNAi genes in the biosynthesis and action of $20 \mathrm{E}$, but there is no information on the biological and morphological effects of $20 \mathrm{E}$ on $T$. castaneum. Accordingly, we examined the effects on development and morphology of various doses of $20 \mathrm{E}$. The goal is to determine the proper doses for experiments examining the molecular bases of the effects of $20 \mathrm{E}$ on various biological events, such as growth, wing development and wing expansion. This study examines the effects of the injection of $20 \mathrm{E}$ during the larval period of $T$. castaneum. We report the effects of injecting various concentrations of $20 \mathrm{E}$ on the percentage of insects entering the prepupal, pupal and adult stages. Morphological changes were also recorded. There are reports that $20 \mathrm{E}$ and an insulin-like growth factor are the key extrinsic regulators of the growth and differentiation of the wing imaginal disc in 
Lepidoptera and Diptera (Tobler \& Nijhout, 2010). In addition, the length and width of adult elytra of T. castaneum were measured after injecting larvae with $20 \mathrm{E}$.

Alpha-amylase ( $\alpha-1,4$-glucan-4-glucohydrolases; EC. 3.2.1.1) is a crucial enzyme for starch digestion in insects that feed on starch or grain powder, including the red flour beetle. This enzyme converts complex carbohydrates into oligosaccharides, which are hydrolyzed to glucose by $\alpha$-glucosidases (Terra et al., 1996). The changes in $\alpha$-amylase activity are related to the feeding behaviour and development in T. castaneum (Tatun et al., 2014). In addition, changes in $\alpha$-amylase activity are associated with different types of plant diets in Helicoverpa armigera (Kotkar et al., 2009). Accordingly, we examined the effects of $20 \mathrm{E}$ on changes in $\alpha$-amylase activity in order to determine whether the enzyme is hormonally regulated and reveal how it responds.

\section{MATERIAL AND METHODS}

\section{Insect cultures}

Stock cultures of T. castaneum were obtained from the Postharvest and Processing Product Research and Development Office, Department of Agriculture, Thailand. The insects were maintained on wheat flour mixed with $5 \%$ yeast and kept at $30 \pm 1{ }^{\circ} \mathrm{C}$ and $70 \pm 5 \%$ relative humidity. Mature larvae (22 days old) were used in this study.

\section{Hormone injection}

A stock solution of 20E (Sigma, St. Louis, MO, USA) was dissolved in absolute ethanol at a concentration of $1 \mathrm{mg} / \mathrm{ml}$ and then diluted with distilled water to obtain concentrations of 100 , 200, 300, 400 and $500 \mathrm{ng} / 100 \mathrm{nl}$. The larvae $(\mathrm{n}=75)$ were anesthetized with diethyl ether in an air-tight chamber for 5 min and then moved onto a glass slide, where they were held in place with sticky tape. Next, 100, 200, 300, 400 or $500 \mathrm{ng}$ of 20E (approximately $100 \mathrm{nl}$ ) were injected into the lateral side of the second abdominal segment of each larva using an aspirator tube that was tightly fitted with a 3.5-in glass capillary tube (Drummond, PA, USA) and pulled by a needle puller (Model P-2000, Sutter Instrument Co., CA, USA). Control larvae were injected with sterilized deionized water. After injection, larvae were kept at room temperature to recover from anesthesia and then kept individually in 24-well plastic plates containing wheat flour mixed with 5\% (w/w) yeast. Every 2 days, until 14 days post-injection, we recorded the number of larvae that changed to the prepupal stage and exhibited a C-shape (crooked posture) and ceased feeding, as well as those that reached the pupal and adult stages. In addition, the body weights of the larvae, prepupae, pupae and adults were measured after injection with $500 \mathrm{ng}$ of $20 \mathrm{E}$ during the larval stage. Three replicates were performed per experiment.

\section{Morphological observations}

The insects injected with $20 \mathrm{E}$ were digitally photographed under an Olympus SZ51 stereomicroscope (Olympus Corporation, Tokyo, Japan). The length and width of the elytra were measured using cellSens Imaging software version 1.8 (Olympus Corporation, Tokyo, Japan). Adobe Photoshop CS3 (Adobe Systems Incorporated, San Jose, CA) was used to document the insect images.

\section{Measurement of $\alpha$-amylase activity}

To measure $\alpha$-amylase activity, larvae ( 2 days post-injection), pupae (3 day-old) and adults (7 day-old) $(n=5)$ were homog- enized in $500 \mu \mathrm{L}$ of $20 \mathrm{mM}$ sodium acetate buffer at $\mathrm{pH} 5.5$ containing $10 \mathrm{mM} \mathrm{NaCl}$ and $20 \mathrm{mM} \mathrm{CaCl}_{2}$. The resulting homogenates were then filtered through cheesecloth and centrifuged at $10,000 \mathrm{xg}$ for $15 \mathrm{~min}$ at $4^{\circ} \mathrm{C}$. The supernatant was transferred to a new tube and kept at $-20^{\circ} \mathrm{C}$ until used as an enzyme extract. The amount of protein in each sample was measured prior to the $\alpha$-amylase assay using a protein dye-binding method (Bio-Rad, Hercules, CA, USA). The activity was determined by incubating $15 \mu \mathrm{L}$ of the insect extract with $100 \mu \mathrm{L}$ of starch solution $(0.2 \%$ starch (Sigma, St. Louis, MO, USA) in $20 \mathrm{mM}$ sodium phosphate buffer, $\mathrm{pH} 6.0$ ) at $37^{\circ} \mathrm{C}$ for $10 \mathrm{~min}$. After incubation, $20 \mu \mathrm{L}$ of 1 $\mathrm{M} \mathrm{HCl}$ was added to the reaction tube to stop the enzymatic reaction, followed by the addition of $100 \mu \mathrm{L}$ of iodine solution $(0.5 \%$ $\mathrm{I}_{2}$ and $5 \% \mathrm{KI}$ ). The $250-\mu \mathrm{L}$ reaction mixture was then transferred to a $1.5-\mathrm{mL}$ plastic cuvette, and the quantity of remaining starch was determined spectrophotometrically at $580 \mathrm{~nm}$ (Thermo Scientific Biomate3s, Thermo Fischer Scientific Inc., MA, USA). The $\alpha$-amylase activity is presented in terms of $\mu \mathrm{g}$ of hydrolyzed $\mathrm{starch} / \mu \mathrm{g}$ of protein $/ \mathrm{min}$. Three replicates were performed per experiment.

\section{Statistical analysis}

One-way Analysis of variance (ANOVA) and a least-significance-difference (LSD) multiple-range test were used for all sta-

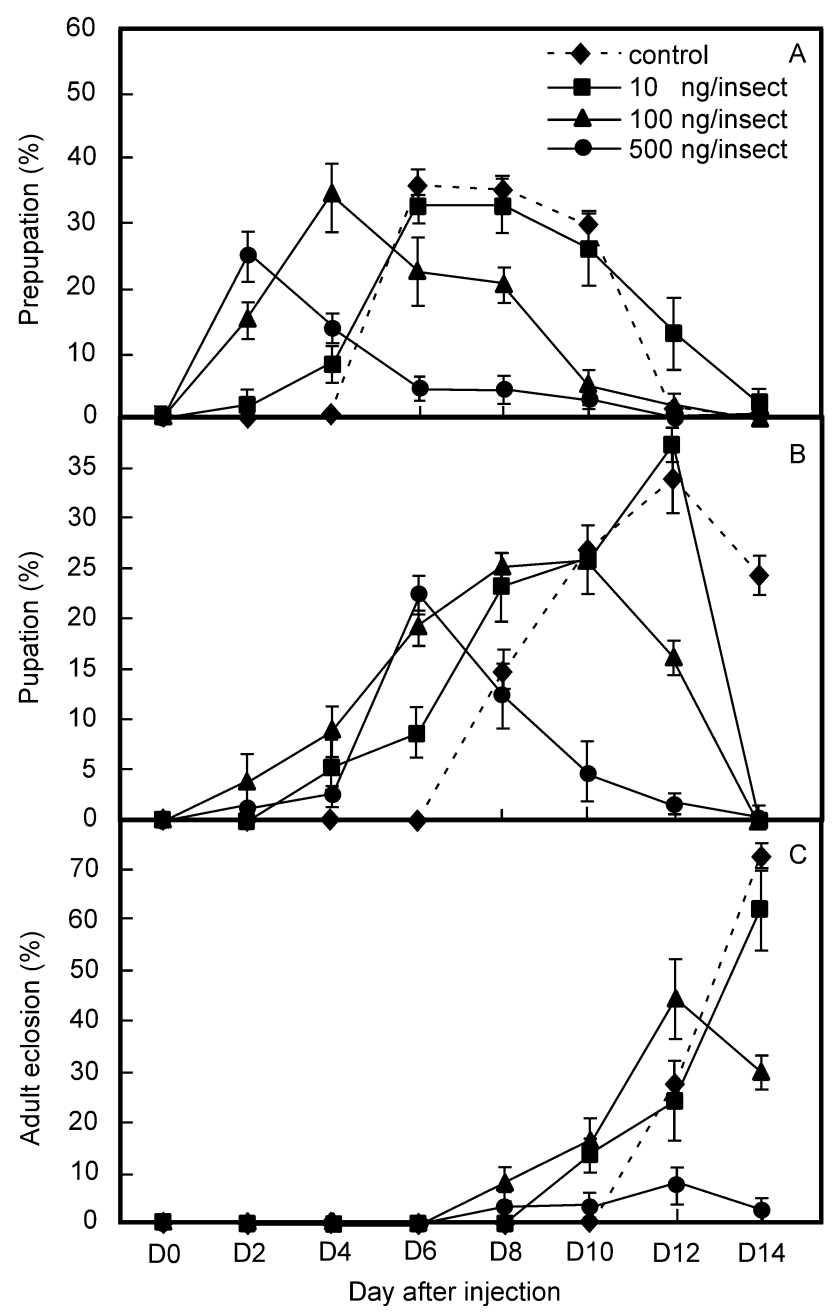

Fig. 1. Percentage of insects entering prepupal (A), pupal (B) and adult stages (C) after being injected with 10, 100 and $500 \mathrm{ng}$ of 20 -hydroxyecdysone $(20 \mathrm{E})$ in the larval stage $(n=75)$. Numbers of prepupae, pupae and adults were recorded every 2 days until adult emergence. The experiment was performed in triplicate and each error bar indicates the SD of the mean. 


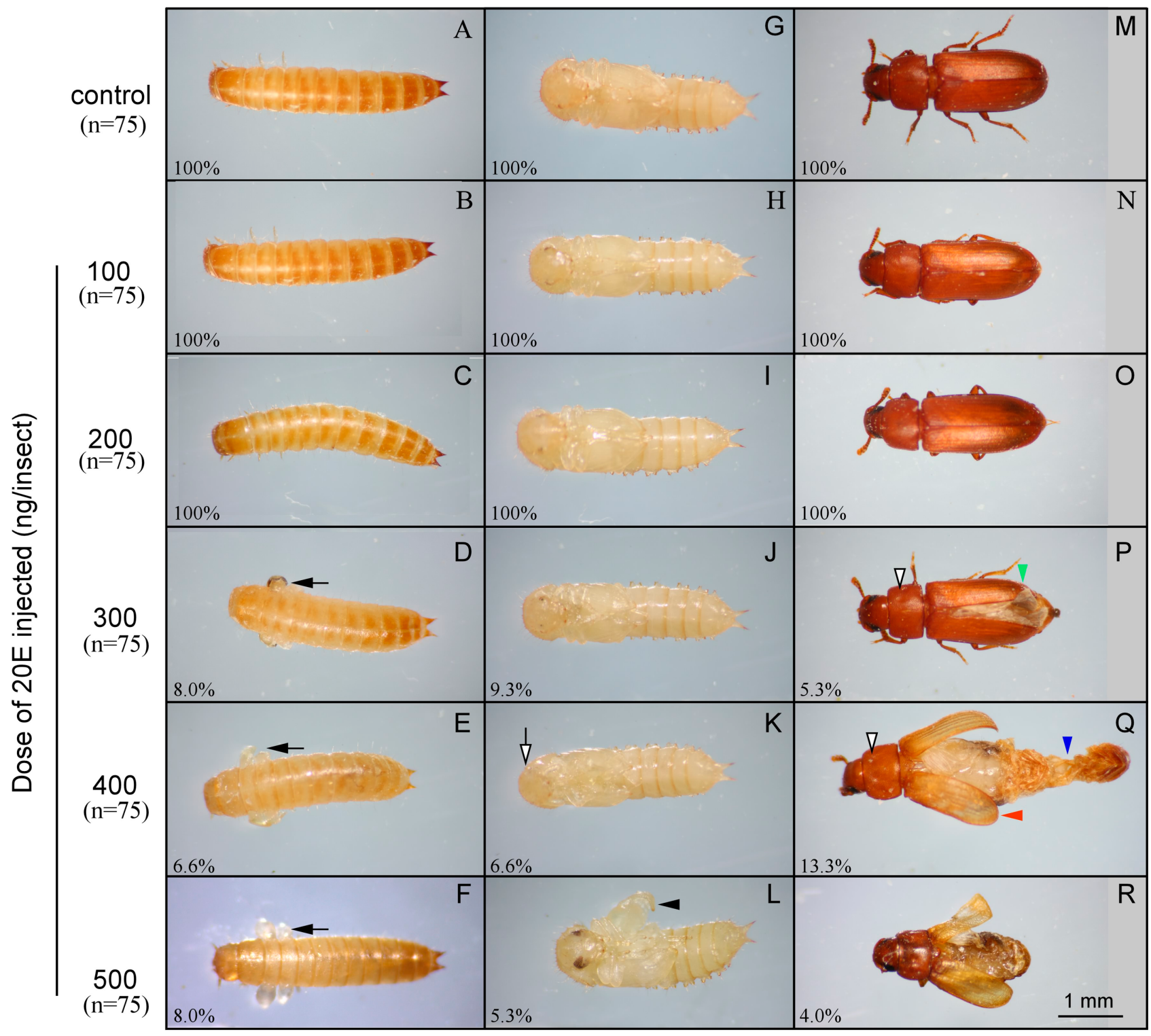

Fig. 2. Morphological changes in the larvae, pupae and adults of $T$. castaneum after injection of 20-hydroxyecdysone (20E) during the larval stage $(n=75)$. Control insects were injected with sterile distilled water $(A, G, H)$. Larvae were injected with 100, 200, 300, 400 and $500 \mathrm{ng} 20 \mathrm{E}$, which resulted in larvae $(\mathrm{B}-\mathrm{F})$, pupae $(\mathrm{H}-\mathrm{L})$ and adults $(\mathrm{N}-\mathrm{R})$. White arrow and black arrowhead indicate detached wing and antennae of $20 \mathrm{E}$ treated pupae. Red arrowhead indicates split and short elytra. White arrowhead indicates small depression on dorsum of thorax. Blue arrowhead indicates pupal cuticle attached to the posterior end of abdomen. Percentage of occurrence of each trait is shown in the bottom left corners of each of $A$ to $R$.

tistical analyses (SPSS program version 11.5). The significance level was set to $0.05(\mathrm{P}<0.05)$.

\section{RESULTS}

\section{Effects of $20 \mathrm{E}$ on the postembryonic development of $T$. castaneum}

At day 2 post-injection, $2.17 \%, 15.79 \%$ and $48.57 \%$ of the larvae injected with 10,100 and $500 \mathrm{ng}$ of $20 \mathrm{E}$, respectively, changed to the prepupal stage (larvae with a crooked posture, inactive, and non-feeding). The prepupal stage was not achieved in the control group until 4-days post injection (Fig. 1A). The highest number of larvae entering the prepupal stage at day 4 post-injection was recorded for the larvae injected with $100 \mathrm{ng}$ of $20 \mathrm{E}$. In the control group and insects injected with $10 \mathrm{ng}$ of $20 \mathrm{E}$, the highest number of larvae entering the prepupal stage was recorded at day 6 post-injection (35.29 and $32.61 \%$, respectively).

The percentage pupating after injection with $20 \mathrm{E}$ revealed that larvae injected with 100 and $500 \mathrm{ng}$ of $20 \mathrm{E}$ started to pupate at day 2 post-injection (9.09\%) (Fig. 1B). Pupation in the control group occurred on day 8 (14.63\%), whereas for those injected with 10 and $100 \mathrm{ng}$ of $20 \mathrm{E}$ it occurred on day $4(5 \%)$ and day $2(3.9 \%)$ post-injection, respectively. The highest percentage pupation of larvae injected with 100 and $500 \mathrm{ng}$ of $20 \mathrm{E}$ was recorded on day 10 and day 6 , respectively. The highest percentage of larvae injected with $10 \mathrm{ng}$ of $20 \mathrm{E}$ and the control group occurred on day 12.

Adult eclosion was recorded on day 8 when the larvae were injected with 100 and $500 \mathrm{ng}$ of $20 \mathrm{E}$ (Fig. 1C). The larvae injected with $10 \mathrm{ng}$ of $20 \mathrm{E}$ changed to the adult stage 


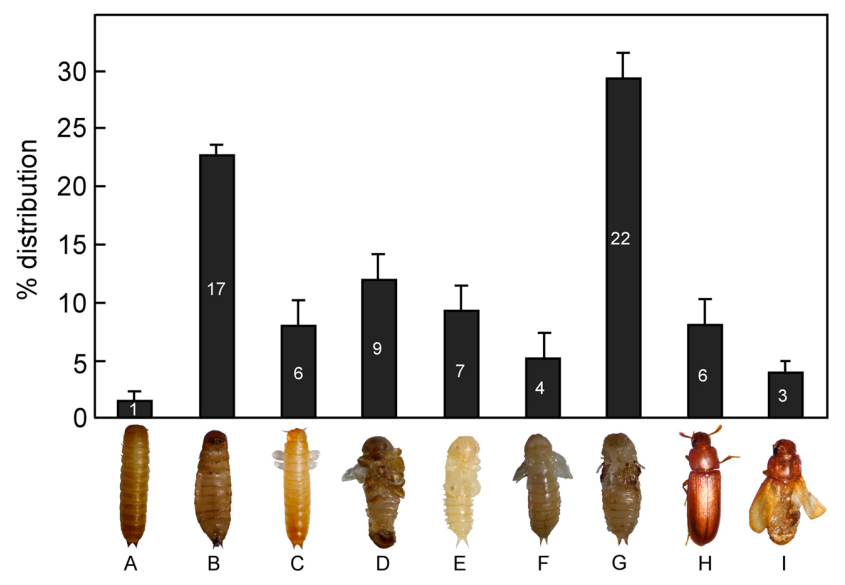

Fig. 3. Columns indicate the percentage occurrence of different characteristics resulting from injecting the larvae with $500 \mathrm{ng}$ 20-hydroxyecdysone $(20 \mathrm{E})(\mathrm{n}=75)$ and in the control group injected with sterile-deionized water. (A) normal looking larvae (B) larvae with flattened abdomens, (C) larvae with projecting small wing pads on meso- and meta-thorax, (D) incomplete pupae with larval cuticle at posterior end, (E) normal pupae, $(F)$ pupae with unfolded wings, (G) pupae with unfold legs and detached antennae, $(\mathrm{H})$ normal adult, (I) incomplete adult. The numbers in the columns are the number of insects.

on day 10, whereas adult eclosion in the control group was first recorded on day 12 and the highest percentage on day 14. There were lower percentages of eclosion in the groups treated with 100 and $500 \mathrm{ng}$ than in the control group and those that received lower doses of $20 \mathrm{E}$. This occurred because incomplete larvae and pupae developed, which failed to develop into adults. The percentage of adult eclosion in the control group was about $75 \%$.

\section{Effects of 20E on the morphology of T. castaneum}

When the last-instar larvae were injected with various doses of 20E, morphological abnormalities were observed at each developmental stage (Fig. 2). In the control group, the injection of sterile water had no effect and resulted in the formation of normal pupae that subsequently moulted into normal adults (Fig. 2A, G, M). The larval body lengths of larvae injected with 100, 200, 300, 400 and $500 \mathrm{ng}$ of $20 \mathrm{E}$ were shorter than those of the control group (Fig. 2BC). Interestingly, larvae injected with 300, 400 and $500 \mathrm{ng}$ of $20 \mathrm{E}$ exhibited 2 pairs of small wing pads that projected out of the larval cuticle on the second and third segments of the thorax (Fig. 2D-F; black arrow). In addition, other larval organs were also observed in those larvae, including antennae, cuticle and eyes, and they died within a few days.

The control larvae developed normally into pupae on day 12, as shown in Fig. 1B. The pupae developed from larvae injected with low doses of 20E (100 and $200 \mathrm{ng}$ of $20 \mathrm{E}$ ) formed pupae that looked normal, while those that developed after high doses of 20E (300, 400 and $500 \mathrm{ng}$ of 20E) exhibited small wings and more rounded abdomens (Fig. 2J, K, L). The overall body sizes of these pupae were not different from those of the water-injected control pupae, but the wing lengths were substantially shorter. At doses of 400 and $500 \mathrm{ng}$ of $20 \mathrm{E}$, the wings and antennae of

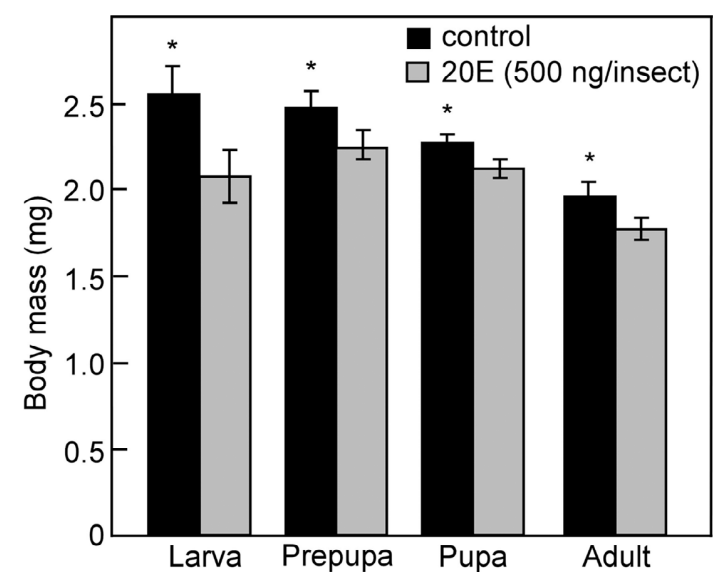

Fig. 4. Changes in the body weight of $T$. castaneum resulting from the injection with 500 ng 20-hydroxyecdysone (20E) during larval stage $(n=75)$. The error bars indicate SDs and asterisks indicate significant difference between control and groups injected with $20 \mathrm{E}$ $(P<0.05)$.

the resulting pupae were not attached to the body (Fig. 2K, $\mathrm{L}$; white arrow and black arrow).

The injection of 100 and $200 \mathrm{ng}$ of $20 \mathrm{E}$ had no apparent effect on adult morphology (Fig. 2M-O). After injecting $300 \mathrm{ng}$ of $20 \mathrm{E}$, adults exhibited split and short elytra (Fig. 2P; green arrowhead), and there were small depressions on the dorsum of the thorax (Fig. 2P, white arrowhead). The injection of $400 \mathrm{ng}$ of $20 \mathrm{E}$ had more severe effects on the adults, resulting in split elytra (Fig. 2Q, red arrowhead), an uncovered abdomen and the pupal cuticle attached to the posterior end of the beetle (Fig. 2Q, blue arrowhead).

The adults that emerged after injection with $500 \mathrm{ng}$ of $20 \mathrm{E}$ had a flattened body, split elytra, and a small depression on the dorsum of the thorax (Fig. 2R). When larvae were injected with 400 or $500 \mathrm{ng}$ of $20 \mathrm{E}$, the resulting adults survived for only about 5 days after eclosion. In addition, there were various morphological abnormalities after injection with $500 \mathrm{ng}$ of $20 \mathrm{E}$, such as a flattened abdomen (17\%) (Fig. 3B) and larvae with small, projecting wing pads on the thorax (6\%) (Fig. 3C). About $9 \%$ of the pupae were incomplete and entrapped within the larval cuticle (Fig. 3D). About 7\% of the pupae were normal (Fig. 3E), 4\% had unfolded wings (Fig. 3F) and 22\% had unfolded legs and detached antennae (Fig. 3G). After the larvae injected with $20 \mathrm{E}$ developed into adults, about $6 \%$ appeared normal, and about 3\% were incomplete adults with small bodies, unfolded wings, a flattened abdomen and a bump on the thorax (Fig. 3I). We next determined body weight after injection with $500 \mathrm{ng}$ of $20 \mathrm{E}$ (Fig. 4). The results showed that the injection decreased the body weight of the larvae, prepupae, pupae and adults $(\mathrm{P}<0.05)$.

\section{Effects of $20 \mathrm{E}$ on elytral width and length in $T$. castaneum}

Since the adults that emerged from larvae injected with $20 \mathrm{E}$ obviously had small elytra, we determined the effect of different doses of $20 \mathrm{E}$ on the length and width of elytra (Fig. 5). At 100 and $200 \mathrm{ng}$ of 20E, the elytral lengths were 2.76 and 2.5 , respectively, which are not much different from the length of $2.66 \mathrm{~mm}$ of the control adults (Fig. 5A). 

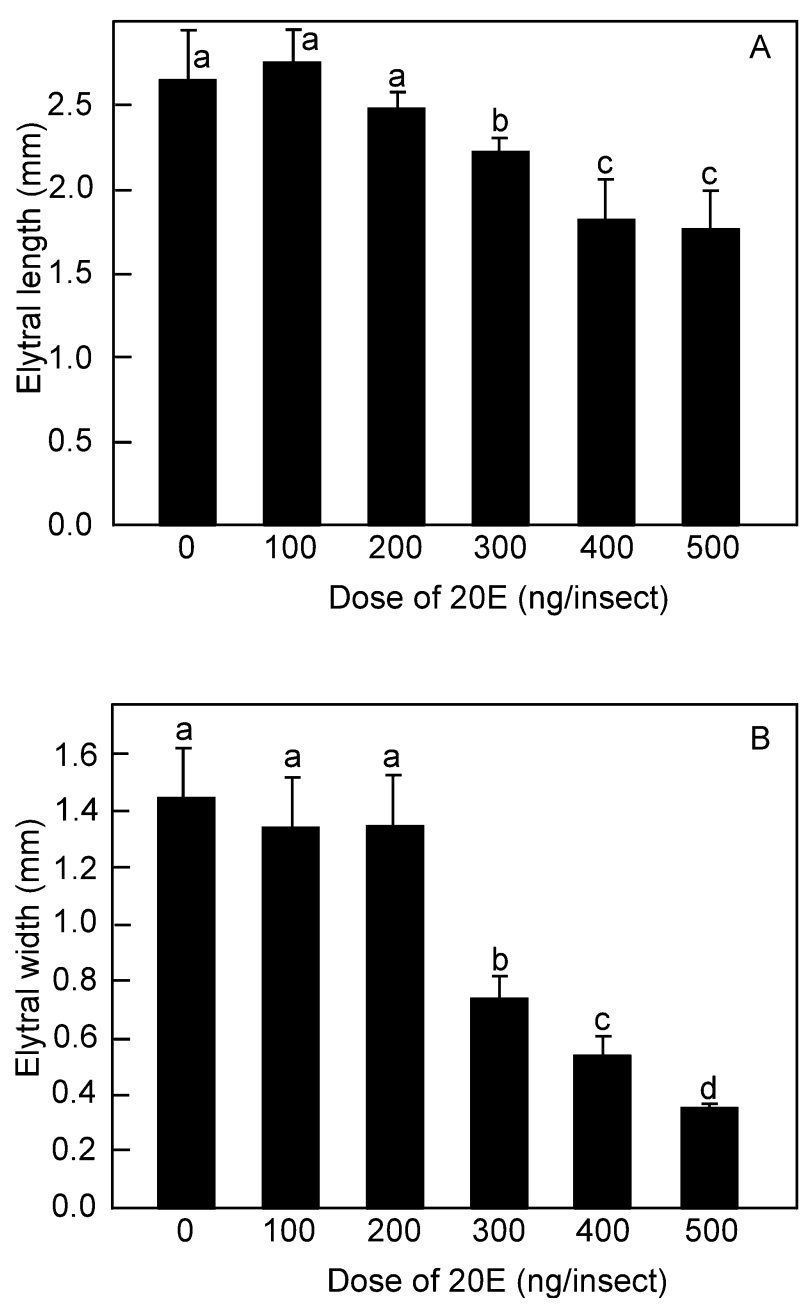

Fig. 5. The length (A) and width (B) of elytra of $T$. castaneum adults that as larvae were injected with either $100,200,300,400$ or 500 ng 20-hydroxyecdysone (20E). The error bars indicate SDs and values labelled with different letters differ significantly $(P<0.05)$.

At 300, 400 and $500 \mathrm{ng}$ of 20E, however, the adults had shorter elytra of $2.23,1.83$ and $1.77 \mathrm{~mm}$, respectively. There was not much difference in the elytral widths between control adults and those treated with 100 and $200 \mathrm{ng}$ of $20 \mathrm{E}(1.45,1.35$, and $1.34 \mathrm{~mm}$, respectively) (Fig. 5B). However, the elytra were significantly narrower in adults that emerged from larvae injected with 300, 400 and 500 ng of $20 \mathrm{E}$. These results demonstrate that injection with $300-500 \mathrm{ng}$ of $20 \mathrm{E}$ significantly reduced the length and width of elytra in adult $T$. castaneum.

\section{Effect of 20E on the activity of the enzyme $\alpha$-amylase}

The activity of $\alpha$-amylase was measured in larvae, pupae and adults that were injected with various doses of $20 \mathrm{E}$ as larvae (Fig. 6). The activity of $\alpha$-amylase in 20E-treated larvae ( 2 days post-injection) was not different from that of the control larvae (Fig. 6A). Similarly, the $\alpha$-amylase activity in the pupae (3 day-old) was at the same level as in the control pupae (Fig. 6B). In contrast, the $\alpha$-amylase activity decreased significantly after injection with 200,300 or $400 \mathrm{ng}$ of 20E. Particularly, the group injected with $500 \mathrm{ng}$ of $20 \mathrm{E}$ had the lower $\alpha$-amylase activity compared to that

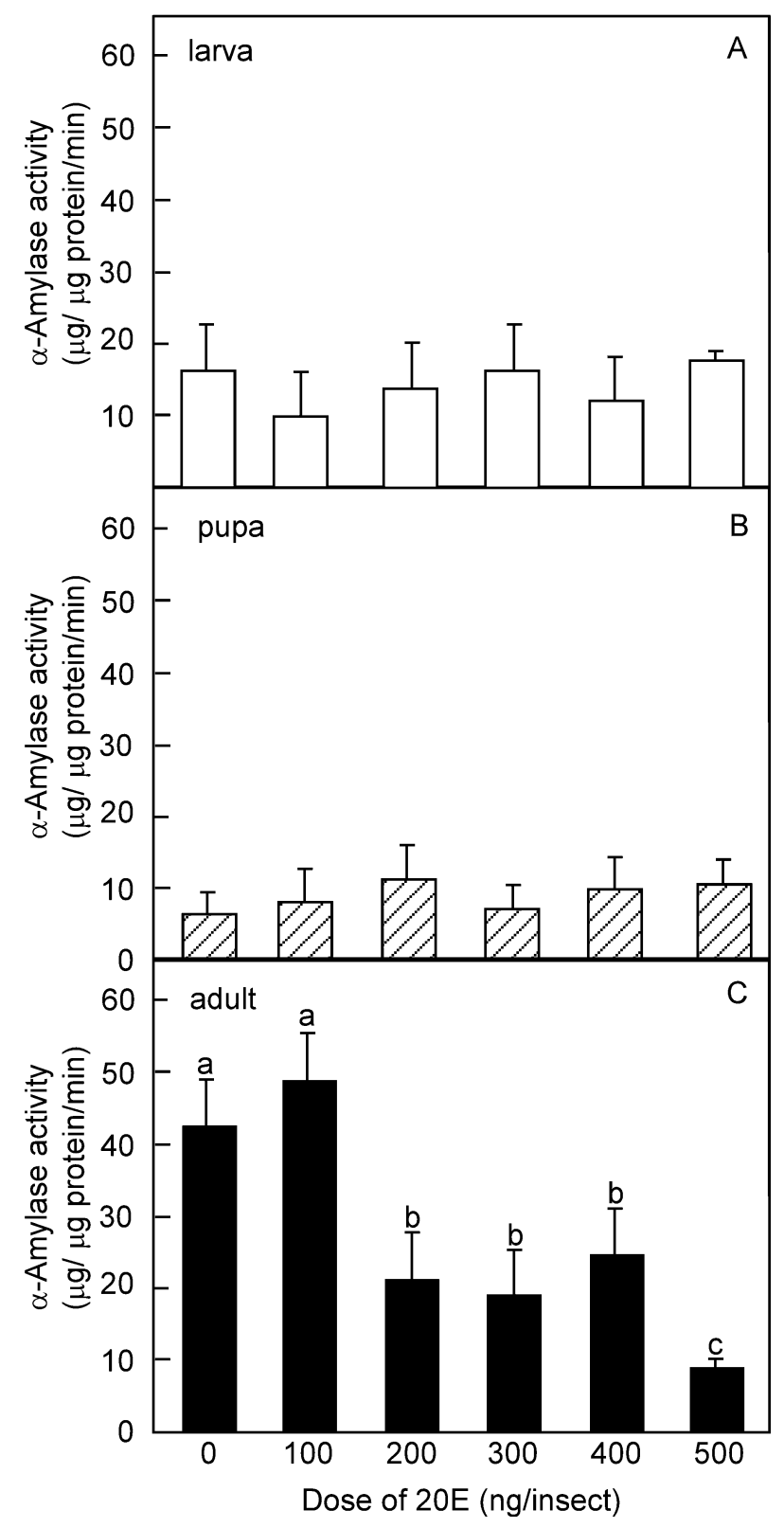

Fig. 6. The enzymatic activity of a-amylase recorded in $T$. castaneum larvae $(A)$, pupae $(B)$ and adults $(C)$ that were injected with 20-hydroxyecdysone (20E) as larvae. The error bars indicate SDs and values labelled with different letters differ significantly ( $P$ $<0.05)$.

recorded after injection of lower doses (Fig. 6C). However, the enzyme activity in larvae injected with $100 \mathrm{ng}$ of $20 \mathrm{E}$ was not different from that of the control group.

\section{DISCUSSION}

The active form of the ecdysteroid, $20 \mathrm{E}$, coordinates the differentiation of adult structures during insect moulting and metamorphosis (Dubrovsky, 2005). Alterations in the levels of $20 \mathrm{E}$ could affect the timing of moulting in different developmental stages in insects, as well as the percentages pupating and emerging as adults (Gelman et al., 2002; Noriega et al., 2002). In the present study, we injected various doses of $20 \mathrm{E}$ into 22-day-old larvae, which were in the last instar. Injection of $20 \mathrm{E}$ resulted the larvae of $T$. 
castaneum entering the prepupal and pupal stages 2 days and 6 days earlier, respectively, than the control group. In the groups injected with $20 \mathrm{E}$, adult eclosion occurred 4 days earlier than in the control group, indicating that $20 \mathrm{E}$ caused precocious metamorphosis in T. castaneum. This result is consistent with a study on Drosophila, in which ecdysone controls developmental transitions and regulates the duration of the growth period (Herboso et al., 2015). Parthasarathy et al. (2008) report that ecdysteroid levels in $T$. castaneum are low during the final instar of the larval stage (ca. 50-100 pg/insect), begin to increase at the beginning of the prepupal stage (ca. 300-600 pg/insect) and reached maximum levels prior to pupation (ca. 500-3500 $\mathrm{pg} /$ insect). The ecdysteroid titers were low at the beginning of the pupal stage and reached the lowest levels prior to adult eclosion. Exogenous $20 \mathrm{E}$ accelerated the larvalpupal transformation, as shown in Fig. 1. This is consistent with a study by Nijhout et al. (1974), in which a small rise in $20 \mathrm{E}$ levels during the final instar of the larval stage terminated larval feeding and initiated premetamorphic behaviour as well as a commitment to pupate. The T. castaneum larvae showed changes in their behaviour, such as, cessation of feeding, changes in the way they moved and the adoption of a crooked posture at day 2 post-injection. These changes were dose-dependent, indicating that the increases in ecdysteroid in larval haemolymph probably commits $T$. castaneum larvae to pupating. This is consistent with studies on other insects, including the tenebrionid beetles Tenebrio molitor, Tribolium freemani and Zophobas atratus (Connat et al., 1984; Hirashima et al., 1995; Aribi et al., 1997).

Morphological changes in various traits in T. castaneum in response to the injection of $20 \mathrm{E}$ were observed. The most apparent morphological changes were the projecting pairs of wing pads on the meso- and meta-thoraces of larvae treated with 300,400 and $500 \mathrm{ng}$ of $20 \mathrm{E}$. In addition, the postures of wings and antennae in the pupal stage were different from those of the control pupae. The occurrence of these prothetelic morphological changes has been reported previously. Prothetelic larvae with the early development of imaginal characteristics result from an improper balance of hormones during development, and prothetely is reported in 22 species belonging to 10 families of $\mathrm{Co}$ leoptera (Wigglesworth, 1954).

This study showed that the injection of $20 \mathrm{E}(300,400$ and $500 \mathrm{ng} /$ insect) into mature larvae of $T$. castaneum caused the formation of prothetelic larvae, which usually also have some other organs more characteristic of pupae, such as small wing pads. The injection of a high concentration of $20 \mathrm{E}$ may cause hyperecdysonic conditions in larvae and subsequently lead to the appearance of pupal organs. In a similar way, a study on $T$. molitor reveals that the injection of $20 \mathrm{E}(10 \mu \mathrm{g} /$ insect $)$ into the last larval instar induces the development of prothetelic larvae and larval-pupal intermediates (Quenedey \& Quennedey, 1990). Moreover, prothetelic larvae of T. molitor also have small projecting wing pads called wing anlagen and do not moult to the adult stage (Quenedey \& Quennedey, 1993).
The effects of exogenous 20E are reported in many species of insects and affect various aspects, including development and survival. However, each species of insect varies in its susceptibility to injection with $20 \mathrm{E}$. The present study demonstrated that the body weight of all the developmental stages (larval, prepupal, pupal and adult) of $T$. castaneum was decreased by injections with 20E (Fig. 4). High concentrations affected the growth of adult wings of $T$. castaneum in that the elytra are shorter and narrower (Fig. 5).

Just before pupal ecdysis in T. molitor, the proliferation of anlagen wing cells decreased (embryonic tissues that are capable of forming adult structures). Furthermore, the mitotic index dropped suddenly, and $40 \%$ of the anlagen cells started to degenerate. This is correlated with an increase in ecdysteroid levels in the haemolymph of $T$. molitor (Quennedey \& Quennedey, 1990). This suggests that the injection of high doses of $20 \mathrm{E}$ into T. castaneum larvae interfered with the process of wing development by initiating the termination of cell proliferation in the imaginal wing disk. Similar effects of 20E are reported in Plutella xylostella, in which high concentrations result in the reduction of larval body weight and average pupal body weight (Sun et al., 2015). A study on Drosophila melanogaster reveals that ecdysone accelerate metamorphic development and reduce body size (Ono, 2014). Furthermore, 20E slowly reduces food consumption and then induces starvation, resulting in fat body lipolysis (Wang et al., 2010). Thus, 20E may cause a reduction in insect body mass by decreasing food consumption.

There are many experiments that indicate that ecdysone is required to promote wing growth in insects. For example, reducing ecdysone levels impairs the growth of wings and ovaries in Blattella germanica and Drosophila (Herboso et al., 2015). Animal size and nutritional status are monitored by the larval fat body by integrating $20 \mathrm{E}$ signaling with the insulin signaling pathway, which indicates that treatment with $20 \mathrm{E}$ may interfere with the signaling pathway and lead to abnormal biosynthesis or metabolism (Nichole et al., 2010). Several studies show that ecdysone positively regulates organ growth in other species (Sun et al., 2015). However, ecdysone has different roles in Lepidoptera, in which a low level of ecdysone is required for the growth of imaginal discs (Nijhout et al., 2007), whereas high concentrations of ecdysone lead to the termination of cell growth and proliferation (Champlin \& Truman, 1998). Furthermore, ecdysone appears to negatively regulate the growth of many tissues including fat body in Drosophila and enhances the growth of wing imaginal discs in fruit flies and Lepidoptera (Nijhout et al., 2014). Taken together, the results indicate that the level of ecdysone is important in determining the nature of the response in insects.

In many insects, the release of digestive enzymes is generally known to be regulated by hormones, including FMRF amides, allatostatins, allatotropins and sulphakinins (Lehane et al., 1995; Terra et al., 1996). Recently, studies on Periplaneta americana revealed that the adipokinetic hormone $(\mathrm{AKH})$ stimulates the activity of the digestive 
enzyme $\alpha$-amylase in the mid gut of insects (Bodláková et al., 2017). This indicates that $\alpha$-amylase is one of the digestive enzymes that are regulated by hormones. In the red crayfish (Procambarus clarkii) the gene expression of amylase $(P c-A m y)$ is significantly down-regulated after injection with 20E (Pen et al., 2015). Furthermore, RNA interference with the ecdysone receptor gene indicates that $P c-A m y$ is one of the ecdysteroid-responsive genes.

The present study revealed that injection with $20 \mathrm{E}$ (200 $500 \mathrm{ng}$ /insect) decreased the activity of $\alpha$-amylase in the resulting adults of $T$. castaneum (Fig. 6), indicating that $20 \mathrm{E}$ may play a role in the regulation of $\alpha$-amylase during the adult stage. Accordingly, based on the percentage pupation and eclosion, morphological changes and changes in the activity of $\alpha$-amylase, the optimal concentration to induce larval-pupal-adult transformations in T. castaneum is $100-200 \mathrm{ng}$ of 20E. Higher doses induce pupation and adult emergence, but caused deformities in the pupae and adults and a reduction in $\alpha$-amylase activity. It is reported that changes in amylase gene expression and $\alpha$-amylase activity in $T$. castaneum (Tc-Amy) correlate well with developmental profile, with a high expression of amylase in the larval stage, a very low level in pupae and the highest activity in adults, with in the latter it is about 2-fold higher than that in larval stage (Tatun et al., 2014). Thus, further investigations are needed to reveal the relationship between $T c-A m y$ and ecdysteroid in the red flour beetle.

ACKNOWLEDGEMENTS. This study was partially supported by the Thailand Research Fund to NT. We are grateful to P. Rangsayatorn for providing scientific facilities.

DECLARATION OF INTEREST. The authors report no conflicts of interest.

\section{REFERENCES}

Aribi N., Quennedey A., Pitolzeta N. \& Delbecque J.P. 1997: Ecdysteroid titres in a tenebrionid beetle, Zophobas atratus: effects of grouping and isolation. - J. Insect Physiol. 43: 815-821.

Bodláková K., JedličKa P. \& Kodrík D. 2017: Adipokinetic hormones control amylase activity in the cockroach (Periplaneta americana) gut. - Insect Sci. 24: 259-269.

Connat J.L., Delbecque J.P. \& Delachambre J. 1984: The onset of metamorphosis in Tenebrio molitor L.: Effects of a juvenile hormone analogue and of 20-hydroxyecdysone. - J. Insect Physiol. 30: 413-419.

DuBRovsky E.B. 2005: Hormonal cross talk in insect development. - Trends Endocrinol. Metab. 16: 6-11.

Gelman D.B., Blackburn M.B. \& Hu J.S. 2002: Timing and ecdysteroid regulation of the molt in last instar greenhouse whiteflies (Trialeurodes vaporariorum). - J. Insect Physiol. 48: $63-73$.

Herboso L., Oliveira M.M., Talamillo A., Perez C., Gonzalez M., Martin D., Sutherland J.D., Shingleton A.W., Mirth C.K. \& BARRIO R. 2015: Ecdysone promotes growth of imaginal discs through the regulation of Thor in $D$. melanogaster. -Sci. Rep. 5: 12383, 14 pp.

Hirashima A., Takeya R., Taniguchi E. \& Eto M. 1995: Metamorphosis, activity of juvenile-hormone esterase and alteration of ecdysteroid titres: effects of larval density and various stress on the red flour beetle, Tribolium freemani Hinton (Coleoptera: Tenebrionidae). - J. Insect Physiol. 41: 383-388.

KotKar H.M., Sarate P.J., Tamhane V.A., Gupta V.S. \& Giri A.P. 2009: Responses of midgut amylases of Helicoverpa armigera to feeding on various host plants. - J. Insect Physiol. 55: $663-670$.

Klingler M. 2004: Tribolium. — Curr. Biol. 14: 639-640.

Lehane M.J., Blakemore D., Williams S. \& Moffatt M.R. 1995: Regulation of digestive enzyme levels in insects. - Comp. Biochem. Physiol. (B) 110: 285-289.

Nichole D.B., Deborah K.H. \& Allen G.G. 2010: The role of 20-hydroxyecdysone signaling in Drosophila pupal metabolism. - Comp. Biochem. Physiol. (A) 157: 398-404.

Nishout H.F. \& Williams C.M. 1974: Control of moulting and metamorphosis in the tobacco hornworm, Manduca sexta (L.): Growth of the last-instar larva and the decision to pupate. $-J$. Exp. Biol. 61: 481-491

Nijhout H.F., Smith W.A., Schachar I., Subramanian S., Tobler I. \& GRUNERT L.W. 2007: The control of growth and differentiation of the wing imaginal disks of Manduca sexta. - Dev. Biol. 302: 569-576.

Nijhout H.F., Riddiford L.M., Mirth C., Shingleton A.W., SuZUKI Y. \& CALLIER V. 2014: The development control of size in insects. - Wiley Interdiscip. Rev. Dev. Biol. 3: 113-134.

Noriega R., Ramberg B.F. \& Hagedorn H.H. 2002: Ecdysteroids and oocyte development in the black fly Simulium vittatum. BMC Dev. Biol. 24: 2-6.

ONO H. 2014: Ecdysone differentially regulates metamorphic timing relative to 20 -hydroxyecdysone by antagonizing juvenile hormone in Drosophila melanogaster. - Dev. Biol. 39: $32-42$.

Parthasarathy R., Tan A., Bai H. \& Palli R.S. 2008: Transcription factor broad suppresses precocious development of adult structures during larval-pupal metamorphosis in the red flour beetle, Tribolium castaneum. - Mech. Dev. 125: 299-313.

Parthasarathy R., Sheng Z., Sun Z. \& Palli R. 2010: Ecdysteroid regulation of ovarian growth and oocyte maturation in the red flour beetle, Tribolium castaneum. - Insect Biochem. Mol. Biol. 40: 429-439.

Pen T., Wang D., Yu Y. \& Liu C. 2015: Identification and expression of an ecdysteroid-responsive amylase from red crayfish Procambarus clakii. - Fish. Sci. 81: 345-352.

Quennedey A. \& QuenNedey B. 1990: Morphogenesis of the wing Anlagen in the mealworm beetle Tenebrio molitor during the last larval instar. - Tissue Cell 22: 721-740.

QuenNedey A. \& QuenNedey B. 1993: The precocious commitment of wing Anlagen in Tenebrio molitor revealed by the addition of 20-hydroxyecdysone. - Tissue Cell 25: 219-236.

Smagghe G. (ED.) 2009: Ecdysone: Structures and Functions. Springer Science \& Business Media, Dordrecht, 583 pp.

Sun L.J., Liu Y.J. \& SHEN C.P. 2015: The effects of exogenous 20-hydroxyecdysone on the feeding, development, and reproduction of Plutella xylostella (Lepidoptera: Plutellidae). — Fla Entomol. 98: 606-612.

Tatun N., Vajarasathira B., Tungutwitayakull J. \& Sakurai S. 2014: Inhibitory effects of plant extracts on growth, development and $\alpha$-amylase activity in the red flour beetle Tribolium castaneum (Coleoptera: Tenebrionidae). - Eur. J. Entomol. 111: $181-188$

Terra W.R., Ferreira C. \& Baker J.E. 1996: Compartmentalization of digestion. In Lehane M.J. \& Billingsley P.F. (eds): Biology of the Insect Midgut. Chapman \& Hall, London, pp. 206-235. 
Tobler A. \& NiJhout F.H. 2010: A switch in the control of growth of the wing imaginal disks of Manduca sexta. - PLoS ONE 5(5): e10723, 9 pp

Wang S., Liu S., Liu H., Wang J., Zhou S., Jiang R.J., Bendena W.G. \& Li S. 2010: 20-hydroxyecdysone reduces insect food consumption resulting in fat body lipolysis during molting and pupation. - J. Mol. Cell Biol. 2: 128-138.
Wigglesworth V.B. 1954: The Physiology of Insect Metamorphosis. Cambridge University Press, Cambridge, 152 pp.

Received May 20, 2018; revised and accepted July 19, 2018 Published online August 20, 2018 